\title{
Reportagem
}

\section{Administração pública: instrumento de ação coletiva da nação}

\author{
Diego Gomes \\ Colaboraram Daniella Álvares Melo e \\ Luis Fernando de Lara Resende
}

"A administração pública é cada vez mais percebida como um locus de influência e participação democrática", avalia o professor norte-americano Guy Peters, ao ministrar palestra na ENAP. O evento contou ainda com a participação das doutoras em administração pública Evelyn Levy e Maria Rita Loureiro, que, em entrevista à RSP, falam dos desafios da gestão pública.

A conformação do Estado está diretamente relacionada a distintos elementos de sua formação histórica, diversidade sociocultural, características ideológicas da sociedade e regime político adotado. A análise desses elementos, em grande medida, auxilia no estudo e na tentativa de entender os estilos administrativos, os objetivos e o papel das administrações públicas ao redor do mundo. Verifica-se ainda que instituições herdadas e já estabelecidas condicionam fortemente os caminhos a serem seguidos, inclusive com a permanência de arranjos institucionais, muitas vezes, pouco eficientes.

A ocorrência de movimentos de dimensões globais que interferem "localmente" é inequívoca, a exemplo da crise dos modelos do Estado de Bem-estar Social, marcada, entre outros, pela intervenção do Estado na economia e pelo aumento exponencial dos gastos buscando prover uma ampla gama de serviços aos cidadãos. No contexto da crise econômico-fiscal decorrente da expansão das atividades dos estados nacionais e também pela incapacidade de a burocracia estatal em lidar com as crescentes e complexas demandas da sociedade (associada à decadência do mundo soviético e de seu modelo estatizante, fadado ao fracasso econômico e político), as ideias divulgadas pelo Consenso de Washington ganharam fôlego e impeliram as reformas administrativas na maioria dos países.

Nesse contexto, o Brasil vivenciava um período de transição democrática, assim como grande parte dos países sul-americanos, com várias alterações no modo de vida social, político e econômico do País. Reinaugurado o regime democrático, as reformas propaladas ao redor do mundo ganharam relevo por aqui. Essas novas práticas - conhecidas como New Public 
Management (NPM) ou Administração Pública Gerencial (AP gerencial) - foram vistas como a segunda grande reforma do aparelho do Estado moderno e, no Brasil, foram encaradas como possibilidade de modernização da AP brasileira.

Superado o foco no equilíbrio das contas públicas (obtido com a redução do gasto público), buscou-se avançar nas mudanças administrativas e políticas, investindo em diferentes estratégias de atuação. No Brasil, o modelo da administração pública gerencial materializou-se com a promulgação do Plano Diretor da Reforma do Aparelho do Estado (PDRAE, 1995), proposto por Bresser-Pereira, então Ministro de Reforma do Estado. De acordo com seus formuladores, a reforma administrativa gerencial preconizava a incorporação dos princípios gerenciais da administração privada na administração pública, tentando, com isso, conferir mais eficiência, eficácia, efetividade ao aparato estatal, além de tentar dar legitimidade democrática às atividades do governo, e conceder maior autonomia e responsabilidade a administradores públicos e agências executoras dos serviços sociais mais descentralizadas.

Entretanto, muitos autores já demonstraram os limites da reforma gerencial no Brasil, apontando o lugar despolitizado que a participação social ocupa no modelo da administração gerencial e a continuidade da reprodução do autoritarismo e do patrimonialismo no aparelho do Estado.

Para Paes Paula (2009), na administração pública gerencial, o processo decisório continuou como um monopólio do núcleo estratégico do Estado e das instâncias executivas, e o ideal tecnocrático foi reconstituído pela nova política de recursos humanos. Em contrapartida, apesar do discurso participativo da nova administração pública, a estrutura e a dinâmica do Estado pós-reforma não garantiram uma inserção da sociedade civil nas decisões estratégicas e na formulação de políticas públicas.

\section{Os 50 anos da administração pública}

Para recapitular os avanços no campo da administração pública desde o término da Segundo Guerra Mundial (1945) e apresentar um panorama analítico da situação atual e das perspectivas futuras para a área, Guy Peters, catedrático do Departamento de Ciência Política da Universidade de Pittsburgh, ministrou a palestra "50 Anos de Administração Pública: teoria e prática", na ENAP, no dia 19 de setembro de 2012.

Considerado um dos maiores especialistas internacionais em administração e políticas públicas, Peters destacou que a administração pública é uma disciplina científica independente, mas que interage fortemente com outras áreas do conhecimento, como o direito, a ciência política, a economia e a sociologia. Ressaltou que seu conhecimento deve basear-se em uma forte correlação entre teoria e prática.

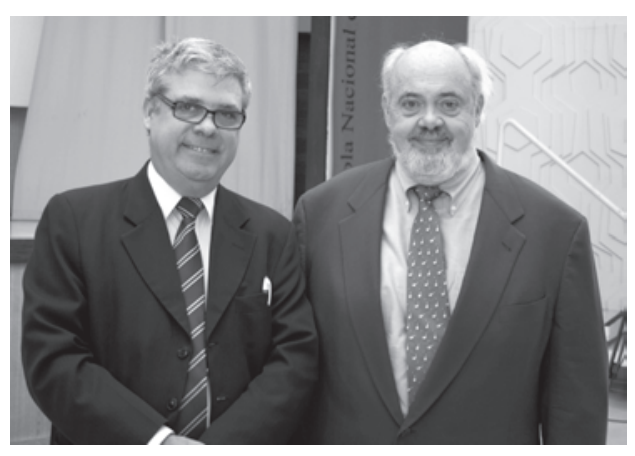

Paulo Carvalho, Presidente da ENAP e Guy Peters, catedrático do Departamento de Ciência Política da Universidade de Pittsburgh. 
No decorrer da história da disciplina Administração Pública, doutrinas orientadas pela prática tiveram significativo impacto na pesquisa científica, em particular no período em que a Nova Administração Pública (New Public Management) era a teoria dominante.

A apresentação do professor foi estruturada a partir de sete dicotomias conceituais e suas contradições: gestão e administração, imparcialidade e receptividade, simplicidade e complexidade, especialização e coordenação, autonomia e integração, racionalidade e evolução, e autoridade e democracia.

Inicialmente, o professor Peters focou uma dicotomia que transcende a administração pública desde que começou a ser estudada como disciplina: aquela entre a orientação legal (Weber) e a administrativa (Wilson) das organizações. Peters considera que, nas últimas décadas, o pêndulo tem-se voltado para os valores gerenciais da eficiência e da eficácia. "A desregulamentação e o fortalecimento dos poderes dos gestores públicos, contudo, têm levado a um enfraquecimento da proteção dos direitos do cidadão e a um confisco do poder decisório das únicas pessoas que, em última instância, possuem legitimidade para administrar as políticas públicas: os políticos eleitos", completa. A partir dessa análise, Peters ressalta a necessidade de se fortalecer os valores legais e de haver políticos atuantes para o bom funcionamento da administração pública, em detrimento do poder burocrático.

\section{A busca pela eficiência}

Em sua exposição, foram abordadas as formas de se combinar duas qualidades indispensáveis aos servidores públicos: sua imparcialidade (neutralidade) perante os cidadãos e os grupos políticos que assumem o poder e, ao mesmo tempo, seu comprometimento para com esses mesmos cidadãos e sua dedicação para servir a objetivos políticos declarados. Para Peters, essas duas demandas aparentemente confrontantes ainda estão por ser balanceadas. "Profissionais de alto escalão do setor público são essenciais para que esse objetivo seja alcançado", salienta. Nesse contexto, Peters comentou sobre os problemas da politização da máquina pública e, também, sobre um ponto igualmente grave: a despolitização da administração pública, o que, na sua visão, permite que percepções tecnocráticas de gestão do bem público terminem por impedir que os líderes políticos possuam instrumentos de direção adequados.

Ao falar da busca da ciência e da prática por soluções organizacionais simples para problemas complexos da administração pública, Peters afirma que a eficiência não tem como ser alcançada por meios de reestruturações organizacionais, em particular a curto prazo. Segundo ele, o consideravelmente simples e tradicional modelo hierárquico piramidal tem sido substituído por dois outros: a substituição dos ministérios centrais por unidades políticas relativamente pequenas, com as tarefas executivas sendo delegadas a agências (semi) autônomas, mais fáceis de serem controladas e avaliadas; e a criação de grandes departamentos administrativos, que contêm numerosas atividades relativamente similares, agrupados para permitir uma melhor coerência ou uma maior facilidade de coordenação.

O professor norte-americano ressaltou que não é difícil alocar a maior parte das atividades públicas em um único departamento, sendo essa a principal razão 
para a inconstância e a procura por estruturas organizacionais ideais.

Peters analisa a divisão existente entre a necessidade de permanente especialização de parcela da administração pública, de forma a refletir a complexidade da sociedade que a permeia, e a necessidade de coordenação intensiva que vem com ela. O número de políticas intersetoriais está crescendo e, consequentemente, mais recursos públicos são alocados para o seu alinhamento e harmonização. Comentando sobre os diversos métodos de coordenação, o professor concluiu que, até pouco tempo, era da maior relevância que "o governo falasse como uma única voz".
Entretanto, devido ao envolvimento de vários segmentos sociais nos processos de prestação de serviços públicos (sociedade civil, cidadãos como indivíduos e terceirização para o setor privado), e à independência de partes do setor público, o problema da integração na administração pública passa a adquirir relevância. Peters propõe, então, uma abordagem em rede para a gestão dos assuntos públicos, limitando de certa forma a primazia das entidades políticas eleitas (governança sem governo), e fazendo das organizações administrativas as colunas de sustentação de políticas públicas específicas e gerentes das redes de políticas públicas.

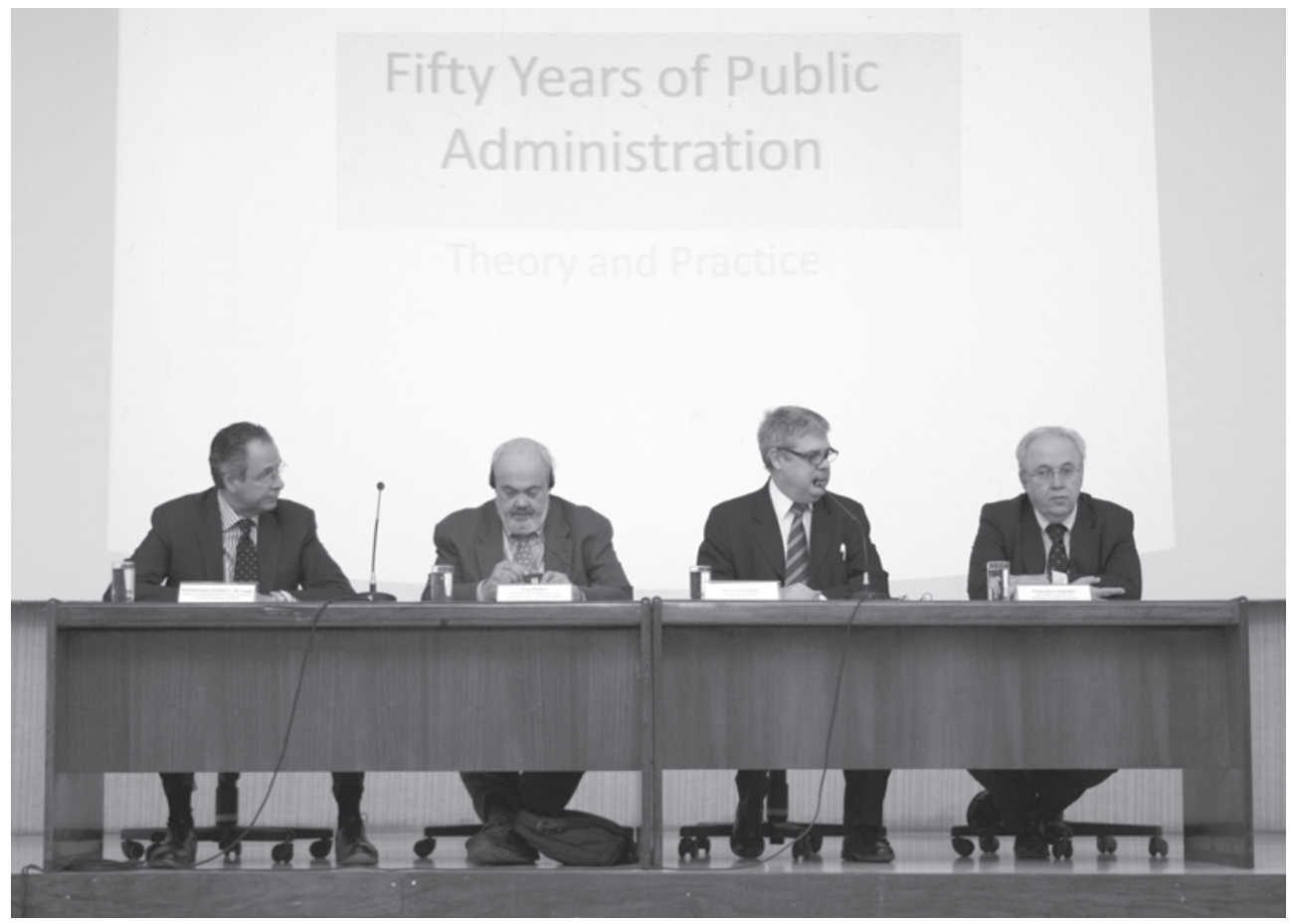

Além do palestrante Guy Peters, compuseram a mesa de abertura o secretário executivo do Ministério do Meio-Ambiente, Francisco Gaetani, o diretor do Departamento de Meio Ambiente e Temas Especiais do Ministério das Relações Exteriores (MRE), embaixador André Corrêa do Lago, e o presidente da ENAP, Paulo Carvalho. 
Esses processos forçam uma gradual e maior exposição da administração pública ao abrir linhas alternativas de responsabilização direta aos cidadãos (accountability). Além disso, na avaliação do professor, a administração pública é cada vez mais percebida como um locus de influência e participação democrática. "Torna-se, de certa forma, uma segunda via para processos democráticos, com as políticas públicas sendo mais facilmente influenciadas durante sua criação e implantação do que ao longo do caminho tradicional seguido pelos representantes eleitos. Dessa forma, a democracia não é vista apenas como uma precondição, mas também como um resultado do funcionamento da administração pública", diz.

Guy Peters finaliza apresentando uma visão geral dos principais conceitos teóricos em administração pública, inclusive os arquétipos de racionalidade e as ideias deles derivadas. Chama a atenção para a existência de novos métodos de supervisão da administração pública e argumenta que eles se tornam mais difíceis de serem adotados, logo, a administração pública se torna mais complexa, abrangente e versátil. "Portanto, uma solução não resolve todos os problemas e 'reinventar a roda' torna-se um fenômeno frequente na administração pública, seja no nível teórico, seja no prático. As dicotomias utilizadas como suporte analítico decorrem da ausência de uma teoria compreensiva que permita unificar as diversas divagações e sobreposições teóricas existentes", completa. Peters insiste em que há várias ideias, mas que não há uma teoria consolidada que permita oferecer respostas para problemas que, com o passar do tempo, se tornam mais complexos. "Administração pública, como uma disciplina específica, exige um apoio teórico firme e inequívoco para maiores pesquisas em uma área de grande complexidade".

\section{A profissionalização da adminis- tração pública brasileira}

Nas duas últimas décadas, houve um aumento da percepção por parte da sociedade em relação à relevância e à necessidade de fortalecimento da gestão pública na agenda política do Brasil. Há uma demanda maior por resultados nas diferentes políticas públicas, há mais protestos contra o desperdício e indignação contra o descaso ou a arbitrariedade de agentes públicos.

\section{“.. uma solução não resolve todos os problemas e 'reinventar a roda' torna-se um fenômeno frequente na administração pública..."}

Maria Rita Loureiro, pós-doutora em sociologia e professora titular da Fundação Getúlio Vargas na área de administração pública e governo, acredita que, de modo geral, a necessidade de fortalecimento da gestão pública tem sido evidenciada não só em jornais e na televisão, mas também nos meios acadêmicos. "Está ficando cada vez mais clara a necessidade de melhorar a ação do setor público, tanto do ponto de vista de capacitação dos servidores quanto de investimento na infraestrutura dos órgãos estatais, em equipamentos e tecnologia, além da necessária modernização de procedimentos", avalia. 
Em consonância com esse movimento, nota-se uma maior participação social na gestão pública, o que contribui para a implantação de melhores práticas de gestão, com impacto positivo na melhoria dos serviços públicos, especialmente em áreas como educação e saúde. "A maior partici-

\section{“A maior participação social, associada à elevação dos níveis educacionais e padrões de cidadania, e da atuação eficaz das diferentes mídias, tem contribuído para uma sociedade mais democrática.”}

pação social, associada à elevação dos níveis educacionais e padrões de cidadania, e da atuação eficaz das diferentes mídias, tem contribuído para uma sociedade mais democrática. A expansão da informação, tanto aquela oferecida pelos poderes públicos quanto aquela que é objeto de análise por diferentes atores, e sua circulação, tem estimulado esse debate", declarou Evelyn Levy, especialista em administração pública com ênfase em organizações públicas.

Nesse sentido, Maria Rita Loureiro destaca que houve movimentos em busca de maior transparência das ações estatais, o que levou à formação de ONG's, a exemplo da ONG Contas Abertas. "Há também o aspecto da probidade administrativa, que ganhou relevo nos últimos anos, evidenciado na Lei da Ficha Limpa e na Lei de Acesso à Informação", informa.
Nova perspectiva: estruturação e planejamento

O recrutamento por meio de concursos, a criação de novas carreiras, os investimentos em capacitação, o crescimento do número de escolas de governo, a ampliação dos cursos de graduação e pós-graduação na área de gestão de políticas públicas se somam e contribuem para a profissionalização do serviço público. "Não se trata, porém, de um processo linear. Esses novos aportes se inserem em um contexto institucional e político que opõe, frequentemente, fortes resistências ao novo. Outras vezes, o cumprimento de uma nova norma se faz sem que novas práticas sejam desenvolvidas; então, nos detalhes da implementação, se perdem os objetivos que se pretendia alcançar", ressalta Evelyn Levy.

Maria Rita Loureiro sublinha que esse movimento de profissionalização teve início após a redemocratização do Brasil, com o advento da Constituição de 1988, e tem se intensificado. "Houve momentos de recuo nesse processo. A era Collor, por exemplo, desarticulou agências e órgãos públicos, demitiu e afastou profissionais em diferentes campos, especialmente em áreas técnicas de planejamento, engenharia e formação de projetos. No período do Governo Fernando Henrique, também houve redução de áreas do setor público", exemplifica. Segundo ela, nos últimos 10 anos, houve uma retomada na formação e qualificação do pessoal de Estado, mas ressalta que se trata de um processo lento.

No âmbito do aperfeiçoamento dos processos de trabalho, o foco atual é no planejamento estratégico de longo prazo, no estabelecimento de metas e indicadores de desempenho, na qualificação de 
processos e na gestão de projetos. "Identificar os resultados que se quer alcançar, avaliá-los, investigar as causas dos acertos e erros (evidence-based policy making) para correção e, sobretudo, aprender são mesmo fundamentais", destaca Evelyn Levy, que também frisa a questão da responsabilização dos agentes públicos, para que esses se enxerguem melhor nos processos, bem como se sintam estimulados a melhorar e inovar.

Para Evelyn Levy, é fundamental que toda organização pública tenha um plano estratégico e que esse seja compartilhado por todos os integrantes da organização, a fim de fortalecer processos e ferramentas para melhoria dos serviços públicos. "A comunicação permanente entre a direção e o conjunto da organização também é muito importante. Reconhecer avanços e aqueles que contribuíram para os mesmos fortalece o sentimento de justiça e identidade. Qualificar todos para que revejam processos e busquem permanentemente novos caminhos para produzir os melhores resultados faz parte da lista, sem se esquecer do mais importante: o cidadão", reitera.

\section{New Public Management e o Brasil}

Doutoras em administração pública, Evelyn Levy e Maria Rita Loureiro acompanharam a palestra ministrada por Guy Peters na ENAP e, a exemplo do exposto pelo professor, divergem sobre os dispositivos da New Public Management (NPM) ainda se refletirem nos processos de modernização e transparência da administração pública brasileira. Atualmente, há um debate no campo da gestão pública sobre o modelo NPM. Alguns autores entendem que ele foi superado, mas muitos entendem que o New Public Management não chegou a constituir um rol único de estratégias para melhorar a gestão pública.

"Em praticamente todos os casos, a inclusão do cidadão, como avaliador dos serviços e das políticas públicas, esteve presente. $\mathrm{O}$ fortalecimento da ideia de resultados, dando maior flexibilidade aos processos, também foi recorrente", pondera Evelyn Levy, observando que a disseminação do uso da tecnologia da informação tem provocado muitas alterações nas formas de prover serviços públicos e de relacionamento com os cidadãos, além de ser parte desse movimento.

$\mathrm{Na}$ sua avaliação, estratégias foram sendo construídas de acordo com as contingências. "Esse é o caso do Brasil também. A NPM teve início como uma resposta inovadora às crises fiscais que dominaram os países desenvolvidos no final dos anos 1970 e 1980. Nos anos 1990, a América Latina também enfrentava essa questão e a isso adicionava o fato de sair de anos pesados de ditadura. Portanto, a velha questão da busca da eficiência presente no modo burocrático - associouse à busca da transparência e do envolvimento do cidadão e também do servidor público", destaca. Como terceiro elemento fundamental, Levy ressalta a busca de resultados, a pactuação de metas e a avaliação do realizado. "Se entendermos que a NPM repousa nesse tripé, eu diria que esse paradigma continua vigente e sua implementação tem trazido novos patamares de desenvolvimento e democracia", finaliza.

"Esse movimento tem lados positivos e negativos. $\mathrm{O}$ positivo certamente está relacionado às questões de eficiência e responsabilidade continuada dos gestores públicos, que estão no bojo das propostas da NPM", explica Maria Rita Loureiro. O lado negativo, na visão da professora titular da FGV, está baseado 
na suposição de que a grande questão do setor público é de se assemelhar à gestão do setor empresarial - voltada para fins lucrativos - e não levar em conta as especificidades públicas, nas quais eficiência tem de ser conjugada com princípios democráticos, levando em consideração a assimetria de recursos, informações e poder entre os cidadãos.
Maria Rita Loureiro afirma que há de se ter uma reflexão específica para o setor público, procurando entender quais as suas reais demandas e necessidades, para que não seja a mera transposição daquilo que é utilizado no setor privado. "Essa reflexão deve permear a discussão sobre qual a melhor gestão para a administração pública brasileira", conclui. 